\title{
Ketamine anesthesia for pericardial window in a patient with pericardial tamponade and severe COPD
}

\author{
[La kétamine utilisée pour l'anesthésie d'une ponction péricardique chez une \\ patiente qui présente une tamponnade et une MPOC sévère]
}

Tim Aye MD CCFP FRCP, Brian Milne MD MSc FRCP

Purpose: To describe the use and concerns of ketamine anesthesia for pericardial window in a patient with pericardial tamponade and severe chronic obstructive pulmonary disease (COPD) with $\mathrm{CO}_{2}$ retention.

Clinical features: A 73-yr-old woman with long-standing COPD and cor pulmonale admitted with pericardial effusion and tamponade had surgery for a pericardial window receiving a total of ketamine 450 $\mathrm{mg}$ iv. Arterial $\mathrm{pCO}_{2}$ increased from $71.8 \mathrm{mmHg}$ preoperatively to $96 \mathrm{mmHg}$ intraoperatively postdrainage of $1000 \mathrm{~mL}$ of effusion. Hemodynamic stability and $\mathrm{SpO}_{2}>93 \%$ were maintained. Intubation was avoided and concerns of increased pulmonary vascular resistance and potential for right ventricular failure in an already compromised right ventricle were not observed clinically.

Conclusion: In this patient with pericardial tamponade, COPD and $\mathrm{CO}_{2}$ retention, the advantages of ketamine included maintaining spontaneous ventilation, avoiding institution and weaning of mechanical ventilation, bronchodilation and relative preservation of the $\mathrm{CO}_{2}$ response curve. Deleterious effects on right ventricular afterload were not observed.

Objectif : Décrire l'utilisation de l'anesthésie avec kétamine et les craintes qu'elle suscite dans le cas d'une ponction péricardique chez une patiente qui présente une tamponnade et une maladie pulmonaire obstructive chronique (MPOC) sévère avec rétention de $\mathrm{CO}_{2}$.

Éléments cliniques: Une femme de 73 ans atteinte d'une MPOC de longue date et d'un cœur pulmonaire et présentant un épanchement péricardique et une tamponnade, a subi une ponction péricardique et a reçu 450 mg iv de kétamine. La pCO ${ }_{2}$ artérielle a augmenté de 7I,8 $\mathrm{mmHg}$, avant l'opération, à $96 \mathrm{mmHg}$ pendant l'opération, le postdrainage de $1000 \mathrm{~mL}$ de liquide. La stabilité hémodynamique et la $\mathrm{SpO}_{2}$ ont été maintenues $>93 \%$. On a évité l'intubation et les craintes d'une augmentation de la résistance vasculaire pulmonaire et de la possibilité d'une défaillance ventriculaire droite dans un ventricule déjà altéré ne se sont pas matérialisées.

Conclusion : La kétamine utilisée dans le présent cas de tamponnade cardiaque, MPOC et rétention de $\mathrm{CO}_{2}$ a permis le maintien de la ventilation spontanée, l'absence d'hospitalisation et le sevrage de la ventilation mécanique, la bronchodilatation et la préservation relative de la courbe de réponse du $\mathrm{CO}_{2}$. Nous n'avons pas noté d'effet nocif sur la postcharge ventriculaire droite.

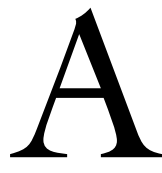

NESTHESIA for pericardial window surgery in patients with pericardial tamponade can prove a challenge due to impaired diastolic filling and decreased stroke volume. ${ }^{1}$ Infiltration with local anesthesia, with or without sedation, and general anesthesia have been used for pericardiotomy in this situation. ${ }^{2}$ Ketamine, because it increases systemic vascular resistance and heart rate, and maintains cardiac contractility, is useful in patients with cardiac tamponade. Kaplan et al. reported on the use of ketamine to supplement local anesthesia for reopening a sternotomy in a postoperative cardiac tamponade patient with subsequent endotracheal anesthesia. ${ }^{3}$ There is, however, a paucity of information on the use of ketamine in patients with cardiac tamponade. Despite the fact that clinicians will often choose ketamine for patients with pericardial tamponade for its beneficial effects on maintaining systemic blood pressure, it can however have deleterious effects on right ventricular afterload. We describe a case of a patient with cor pulmonale and chronic

From the Department of Anesthesiology, Queen's University, Kingston, Ontario, Canada.

Address correspondence to: Dr. Brian Milne, Department of Anesthesiology, Kingston General Hospital, 76 Stuart Street, Kingston,

Ontario K7L 2V7, Canada. Phone: 613-548-7827; Fax: 613-548-1375; E-mail: milneb@post.queensu.ca

Accepted for publication October 31, 2001.

Revision accepted December 12, 2001.

CAN J ANESTH 2002/49: 3 / pp 283-286 
obstructive pulmonary disease (COPD) who had a pericardial window under ketamine anesthesia where this was taken into consideration.

Case report

A 73-yr-old, 72-kg woman with long-standing COPD and cor pulmonale was admitted with pericardial effusion and tamponade. Admission one month prior for drainage of a pericardial effusion was complicated by insertion of a pulmonary artery catheter introducer into the carotid artery and postpericardiocentesis intrapericardial hemorrhage. Her pulmonary artery pressure at that time was $54 / 25 \mathrm{mmHg}$. She was discharged home on nasal $\mathrm{O}_{2} 4 \mathrm{~L} \cdot \mathrm{min}^{-1}$. Prior to the present admission she experienced increasing dyspnea, orthopnea and peripheral edema. Other medical problems were obesity, stable angina, and hypothyroidism. Medications included enalapril, furosemide, isosorbide dinitrate, ranitidine, thyroxin, salbutamol and ipratropium bromide. She reported allergies to penicillin, codeine and morphine. Blood pressure on admission was $130 / 80 \mathrm{mmHg}$, heart rate 90 beats. $\mathrm{min}^{-1}$, respiratory rate 24 breaths $\mathrm{min}^{-1}$ and a pulsus paradoxus of $10 \mathrm{mmHg}$. Breath sounds were decreased bilaterally with bibasilar crackles. Her $\mathrm{SpO}_{2}$ was $98 \%$ on nasal $\mathrm{O}_{2} 4 \mathrm{~L} \cdot \mathrm{min}^{-1}$, and jugular venous pressure (JVP) was $3 \mathrm{~cm} \mathrm{H} \mathrm{H}_{2} \mathrm{O}$.

The following day she was in distress with increasing shortness of breath. She was unable to lie down stating she had never been this bad before. There had been no improvement with salbutamol inhalation and she had been started on prednisone. Her blood pressure was $116 / 68 \mathrm{mmHg}$, heart rate 110 beats. $\mathrm{min}^{-1}$, pulsus paradoxus $26 \mathrm{mmHg}$ and $\mathrm{SpO}_{2} 93 \%$ on nasal $\mathrm{O}_{2} 4 \mathrm{~L} \cdot \mathrm{min}^{-1}$. Examination revealed decreased air entry with faint wheezes, JVP $8 \mathrm{~cm} \mathrm{H}_{2} \mathrm{O}$, with poorly palpable peripheral pulses. The patient refused to have another pericardiocentesis "awake" because of her previous experience and requested surgical drainage be performed under a general anesthetic.

Initially a thoracoscopic pericardial window was considered but in consultation with the attending anesthesiologist it was decided that problems with collapsing the emphysematous lung, difficulty in tolerating one lung anesthesia, and lack of an expeditious resolution made a subxiphoid approach to the pericardial window preferable. Anemia was corrected with two units of packed cells bringing the hemoglobin concentration to $106 \mathrm{mg} \cdot \mathrm{dL}^{-1}$. Electrolytes and liver function tests were normal, an arterial blood gas on 4 $\mathrm{L} \cdot \mathrm{min}^{-1}$ nasal $\mathrm{O}_{2}$ showed $\mathrm{pH} 7.38, \mathrm{PO}_{2} 78.9 \mathrm{mmHg}$, $\mathrm{PCO}_{2} 71.8 \mathrm{mmHg}, \mathrm{HCO}_{3} 37.5 \mathrm{mmoL} \cdot \mathrm{L}^{-1}$. Her electrocardiogram showed a sinus tachycardia with low voltage and her chest $x$-ray suggested a large pericardial effusion.

The patient eventually consented to needle drainage of the pericardial effusion prior to definitive surgery providing she was not aware. An echocardiogram demonstrated a very large anterior and posterior pericardial effusion and a chronically dilated right ventricle with systolic and diastolic collapse. Under echo guidance, in the intensive care unit (ICU) in the sitting position, $400 \mathrm{~mL}$ of chocolate coloured pericardial fluid was drained. Three boluses of midazolam 0.5 $\mathrm{mg}$ and propofol $20 \mathrm{mg} i v$ were given during the procedure. Hemodynamics remained stable throughout the procedure and at the termination, right ventricular collapse was still present on echocardiogram. In the operating room with continuous intra-arterial monitoring, automated segment lead I, II, and V analysis, nasal $\mathrm{O}_{2} 4 \mathrm{~L} \cdot \mathrm{min}^{-1}$, the patient was prepped and draped in the sitting position. After administration of glycopyrrolate $0.3 \mathrm{mg}$, and midazolam $1 \mathrm{mg}$, anesthesia was induced with ketamine in $25 \mathrm{mg}$ increments to a total of $100 \mathrm{mg}$. Blood pressure was $120 \mathrm{mmHg}$ systolic, and heart rate 100 beats. $\mathrm{min}^{-1}$. The patient was gradually returned to the supine position and lidocaine $1 \%$ was infiltrated locally. Subxiphoid drainage of $1000 \mathrm{~mL}$ of effusion increased her blood pressure to $140 \mathrm{mmHg}$ systolic. Heart rate was $100-115$ beats. $\mathrm{min}^{-1}$ and $\mathrm{SpO}_{2}>93 \%$ throughout. An intraoperative blood gas postdrainage showed a $\mathrm{pH} 7.28$, $\mathrm{PO}_{2} 102 \mathrm{mmHg}, \mathrm{pCO}_{2} 96 \mathrm{mmHg}, \mathrm{HCO}_{3} 44$ $\mathrm{mmoL} \cdot \mathrm{L}^{-1}$. A total of $450 \mathrm{mg}$ of ketamine were used during the procedure. The xiphisternum and a large ellipse of anterior pericardium were excised along with talc poudrage of the pericardial space. She returned to the ICU with stable hemodyamics and had no recall of events. There were no postoperative problems except for a pneumothorax, which required insertion of a left-sided chest tube, probably due to the pericardiocentesis. She was discharged home five days postoperatively and analysis of the pericardial fluid was negative for malignancy, showing only inflammatory cells.

\section{Discussion}

Pericardial tamponade is primarily a problem of impaired diastolic filling due to continuous elevation of intrapericardial pressure decreasing stroke volume, cardiac output and systemic blood pressure. ${ }^{1}$ The choice of anesthetic in this patient had to take into account the combined pathophysiology of pericardial tamponade and chronic obstructive lung disease with $\mathrm{CO}_{2}$ retention. Hypercarbia may increase right ventricular afterload, and cause dysrhythmias which could be detrimental to the failing right ventricle. ${ }^{2}$ While the 
use of ketamine has been deemed as potentially disastrous in patients with cardiac tamponade and minimal right ventricular functional reserve, ${ }^{4}$ Kaplan reported the use of ketamine $0.5 \mathrm{mg} \cdot \mathrm{kg}^{-1}$ to supplement local anesthesia for opening the lower end of a sternotomy incision in a patient with postoperative tamponade. Following this, in contrast to our case, general anesthesia was induced with ketamine and succinylcholine, the trachea intubated and anesthesia maintained with nitrous oxide, pancuronium, and morphine. ${ }^{3}$ The sole use of local anesthesia advocated by Stanley et al. ${ }^{2}$ or awake intubation ${ }^{5}$ was not an option due to our patient's desire to be "asleep".

Although ketamine can have myocardial depressant effects in vitro and in patients who are maximally stressed with depleted catecholamines, ${ }^{6}$ in this case ketamine produced no decrease in blood pressure. The patient refused to be monitored with a pulmonary artery catheter due to her previous experience of an introducer having been placed into the carotid artery. This prevented monitoring of cardiac output and pulmonary artery pressures. The effect of ketamine on the pulmonary vasculature was a main consideration due to COPD with associated loss of pulmonary capillaries and arterial hypoxia leading to pulmonary vasoconstriction. Spotoft et al. found increases in pulmonary artery pressures mainly through increases in pulmonary vascular resistance unrelated to changes in $\mathrm{PaO}_{2}$ and $\mathrm{PaCO}_{2}$ with ketamine. ${ }^{4}$ There was initial concern that this increase in pulmonary vascular resistance may be greater than the increase in systemic vascular resistance which could cause an increase in shunt fraction. However, Rees et al. found no increase in shunt fraction using ketamine in humans during one lung anesthesia when compared to enflurane. ${ }^{7}$ One of the main problems with studies on the effects of ketamine on the pulmonary vasculature is controlling for the effects of respiratory depression on partial airway obstruction. Balfors et al. found no change in pulmonary vascular resistance during ketamine anesthesia in adults with assisted ventilation. ${ }^{8}$ Despite the effects of ketamine on pulmonary vasculature, its beneficial bronchodilating effect which parallels that of inhalational agents has been used in the treatment of reactive airways. ${ }^{9}$ In our patient with COPD, ketamine's bronchodilating effects may also have been advantageous.

Increases in $\mathrm{PaCO}_{2}$ were seen intraoperatively and this may have been due to the change of position from sitting to supine, diaphragmatic dysfunction from an upper abdominal incision, as well as the respiratory depressant effects of midazolam and ketamine. Surgical anesthesia and spontaneous ventilation can be achieved in numerous ways, but the majority are associated with direct myocardial depressant effects and decreases in systemic vascular resistance. Inhalational agents shift the $\mathrm{CO}_{2}$ response curve to the right and the associated hypercarbia may be detrimental to the patient with COPD and $\mathrm{CO}_{2}$ retention. Acute or chronic respiratory acidosis may cause central nervous side effects, increase right ventricular afterload, and cause dysrhythmias, all complications which should be avoided in patients with limited myocardial reserve. Although ketamine is a respiratory depressant, its' effects are mild ${ }^{10,11}$ and even though there is no guarantee against pulmonary aspiration, respiration is maintained with relatively intact laryngeal reflexes. In humans, ketamine alone causes mild respiratory depression similar but at a lesser degree to that seen with narcotics in the premedicant or analgesic dose range in that the slope of the ventilatory response to $\mathrm{CO}_{2}$ is unchanged, while the response curve is shifted to the right. ${ }^{12}$ Maintaining spontaneous ventilation may be better tolerated in the patient with cardiac tamponade. ${ }^{13}$ Increased tracheobronchial secretions may be attenuated with an antisialogogue and apneic spells may be minimized by titrating doses with slow injections.

Thus, in this patient with pericardial tamponade, COPD and $\mathrm{CO}_{2}$ retention, the advantages of ketamine included maintaining spontaneous ventilation, avoiding institution and weaning of mechanical ventilation, bronchodilation and relative preservation of the $\mathrm{CO}_{2}$ response curve, lack of cardiac depression, intense somatic analgesia, and amnesia. These advantages were felt to outweigh the disadvantages of effects on pulmonary vasculature, increased tracheobronchial secretions, and emergence reactions. The theoretical concerns of increased pulmonary vascular resistance and potential for right ventricular failure in an already compromised right ventricle were not observed clinically, and we were able to avoid intubation and mechanical ventilation in our patient with COPD and $\mathrm{CO}_{2}$ retention.

\section{References}

1 Lake CL.Anesthesia and pericardial disease. Anesth Analg 1983; 62: 431-43.

2 Stanley TH, Weidauer HE. Anesthesia for the patient with cardiac tamponade. Anesth Analg 1973; 52: 110-3.

3 Kaplan JA, Bland JW Jr, Dunbar RW.The perioperative management of pericardial tamponade. South Med J 1976; 69: 417-9.

4 Spotoft H, Korshin JD, Sørensen MB, Skovsted P. The cardiovascular effects of ketamine used for induction of anaesthesia in patients with valvular heart disease. Can Anaesth Soc J 1979; 26: 463-7. 
5 Breen PH, MacVay MA. Pericardial tamponade: a case for awake endotracheal intubation (Letter). Anesth Analg 1996; 83: 658.

6 Stoelting $R$. Nonbarbiturate induction drugs. In: Stoelting R (Ed.). Pharmacology \& Physiology in Anesthetic Practice, $3^{\text {rd }}$ ed., Philadelphia, Pennsylvania: Lippincott-Raven, 1999: 140-57.

7 Rees DI, Gaines III GY. One-lung anesthesia-a comparison of pulmonary gas exchange during anesthesia with ketamine or enflurane. Anesth Analg 1984; 63: 521-5.

8 Bälfors E, Häggmark S, Nyhman H, Rydvall A, Reiz S. Droperidol inhibits the effects of intravenous ketamine on central hemodynamics and myocardial oxygen consumption in patients with generalized atherosclerotic disease. Anesth Analg 1983; 62: 193-7.

9 Sarma VJ. Use of ketamine in acute severe asthma. Acta Anaesthesiol Scand 1992; 36: 106-7.

10 Soliman MG, Brindle GF, Kuster G. Response to hypercapnia under ketamine anaesthesia. Can Anaesth Soc J $1975 ; 22: 486-94$.
11 Reich DL, Silvay G. Ketamine: an update on the first twenty-five years of clinical experience. Can J Anaesth 1989; 36: 186-97.

12 Bourke DL, Malit LA, Smith TC. Respiratory interactions of ketamine and morphine. Anesthesiology 1987; 66: 153-6.

13 Möller CT, Schoonbee CG, Rosendorff C.

Haemodynamics of cardiac tamponade during various modes of ventilation. Br J Anaesth 1979; 51: 409-14

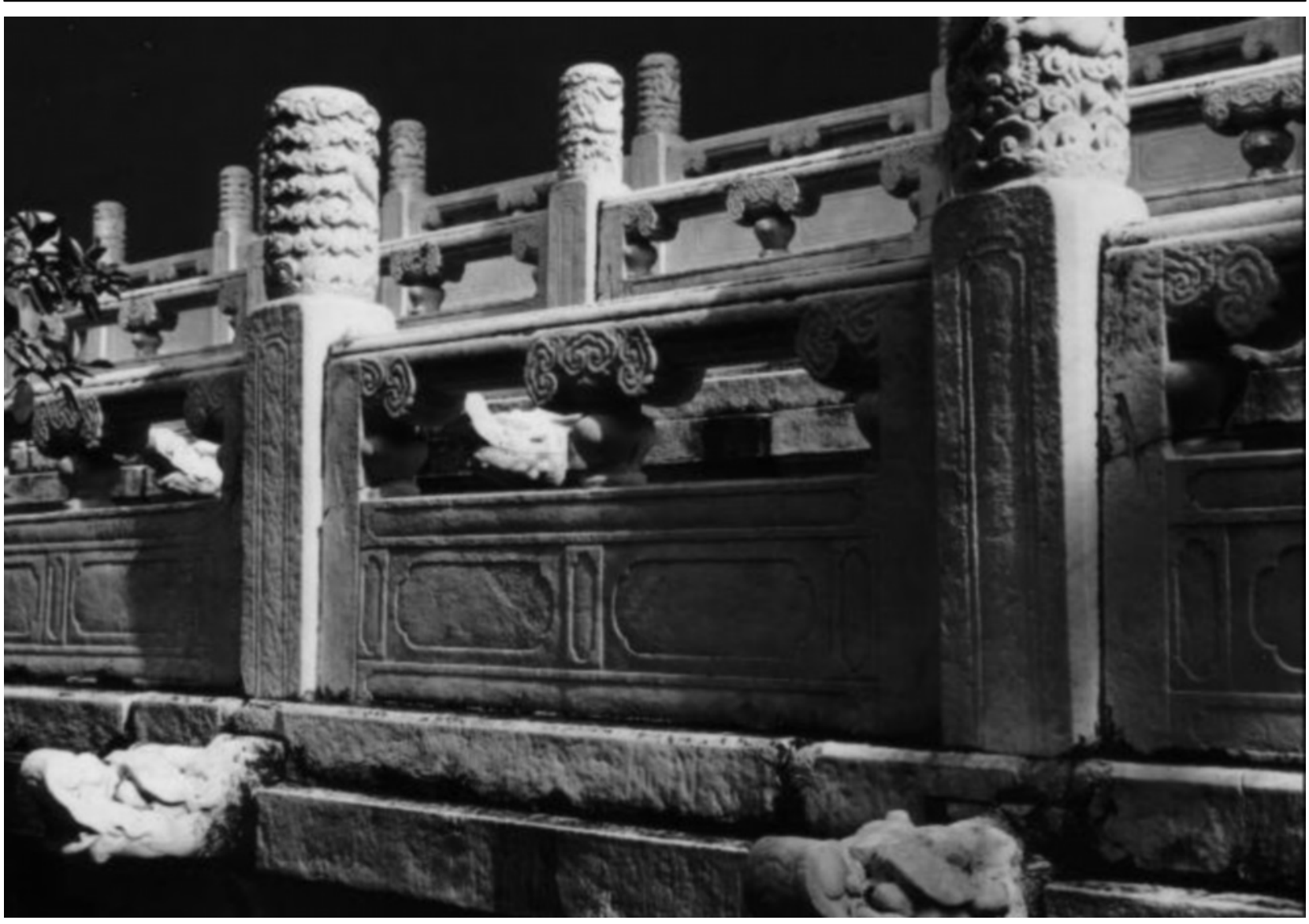

Temple Balustrade - Beijing 